\title{
Comparative Dental Caries Activity in Dropouts and Non-Dropouts from a Three-Year Study
}

NATHANIEL H. ROWE, RAY H. ANDERSON, and LESTER A. WANNINGER, JR. School of Dentistry, The University of Michigan, Ann Arbor, Michigan 48104, USA and General Mills Inc, Minneapolis, Minnesota

Design of a clinical study to determine the impact of an experimental agent or regimen on dental caries activity must balance a number of interacting variables to yield meaningful results. At the outset, caries experience must be determined for each subject to permit sample stratification that will, in addition to age and sex, divide dental caries risk equally between the experimental groups. Unfortunately, some individuals discontinue participation during the course of the study. How damaging this will be to group caries risk equality depends on several factors, some obvious and others inapparent. For example, a correlation might exist between those habits or attitudes that are expressed overtly in discontinuance of participation and the measure under examination-dental caries activity. Could it be that dropouts have a peculiar or unusual dental caries rate or risk, and, by withdrawing unequally from experimental groups, do they destroy otherwise legitimate sample comparability? This study examines comparability of dental caries experience during a one-year period in two study samples; one group subsequently discontinued participation and the other completed all three years of the study.

This study was sponsored by The University of Michigan, financially supported by General Mills, Inc., Minneapolis, Minn, and conducted with the cooperation of the Ann Arbor Public Schools System.

Examiners during the field study were $I$. A. Regezi, captain USAF, DC, Travis Air Force Base, Calif and J. Philip Sapp, Department of Pathology, The University of Western Ontario, London, Ontario, Canada. Received for publication July 24, 1972.
Ann Arbor seventh grade public school children of both sexes were enrolled into a permissive dental caries prevention study by parental consent. Dental caries activity was determined initially and annually thereafter. Examinations were conducted by two experienced dentists. One conducted all clinical examinations; the other conducted all radiographic examinations at the $0,12,24$, and 36 month intervals. Participants were instructed individually in oral hygiene by a hygienist; this was followed by supervised brushing. The participant was seated in a head-rest-equipped portable dental chair and teeth were examined with a mirror and explorer. High intensity light was carried uniformly to each of the individual's teeth by a fiber optic light catheter within a hollow-handled mouth mirror. Verbalized observations were recorded on IBM forms (by another dentist). Seven $X$ rays (bitewing and anterior) were taken per individual per year. Of the participants, 544 were examined at both the initial and one-year anniversary. Those present at examinations one and two, but who subsequently discontinued participation, comprised the dropout sample (188 individuals). The remaining 356 individuals continued participation for three years.

The table indicates the similarity between the two groups. No statistically significant differences were found between groups in initial, final, or incremental DMF teeth or DMF surfaces.

Discontinuance of participation thus was unrelated to caries activity.

Dental Caries Activity in Dropouts and Non-Dropouts

\begin{tabular}{|c|c|c|c|c|c|c|c|}
\hline & $\begin{array}{l}\text { Drop- } \\
\text { outs } \\
(188) \\
\text { Mean }\end{array}$ & $\begin{array}{c}\text { Partici- } \\
\text { pants } \\
(356) \\
\text { Mean }\end{array}$ & $\begin{array}{l}\text { Drop- } \\
\text { outs } \\
\text { SD* }\end{array}$ & $\begin{array}{l}\text { Partici- } \\
\text { pants } \\
\text { SD }\end{array}$ & Difference & Percent & $t$ \\
\hline Age (in years) & 13.14 & 13.09 & 0.43 & 0.38 & -0.05 & 0.39 & -1.36 \\
\hline Sex & $0.54 \dagger$ & $0.51 \dagger$ & 0.50 & 0.50 & -0.03 & -6.13 & -0.69 \\
\hline Initial DMF teeth & 4.74 & 4.59 & 3.36 & 2.89 & -0.15 & -3.31 & -0.53 \\
\hline Initial DMF surfaces & 6.61 & 6.26 & 5.15 & 4.60 & -0.35 & -5.51 & -0.77 \\
\hline Final DMF teeth & 5.73 & 5.71 & 3.91 & 3.33 & -0.02 & -0.37 & -0.06 \\
\hline Final DMF surfaces & 8.01 & 7.60 & 6.40 & 5.27 & -0.40 & -5.28 & -0.74 \\
\hline Increments DMF teeth & 1.51 & 1.59 & 1.54 & 1.58 & 0.08 & 4.82 & 0.55 \\
\hline Increments DMF surfaces & 2.55 & 2.35 & 2.72 & 2.42 & -0.20 & -8.72 & -0.87 \\
\hline
\end{tabular}

* SD, standard deviation.

$\dagger$ Male $=1$; female $=0$. 